\title{
The Effect of Chemical Treatments on the Tuber Dormancy of Hungarian Potato Cultivars
}

\author{
Ádám Esztergályos ${ }^{1} \cdot$ Zsolt Polgár $^{1}$
}

Received: 30 January 2020 / Accepted: 18 September 2020/ Published online: 12 October 2020

(C) The Author(s) 2020

\begin{abstract}
The length of tuber dormancy of potato (Solanum tuberosum L.) is an important property of cultivars, which significantly determines the duration of storage period, the storage conditions, the economy of storage and the earliest time of planting. Potato cultivars can largely differ in the duration of dormancy period. Under temperate climatic conditions, longer dormancy is more advantageous. However, in case of multiple planting within one calendar year or in case of specific needs, it can be necessary to artificially break the dormancy of tubers. In this study, we investigated the effect of chemical treatments on the tuber dormancy of three Hungarian potato cultivars (Balatoni rózsa, Démon, Botond) having different dormancy periods. The experiment was conducted in three consecutive years (growing periods). Treatments were performed using gibberellic acid, benzyl-adenine and Rindite in different concentrations and combinations. Results showed that the treatments largely influenced the length of tuber dormancy. Rindite and its combination with gibberellic acid treatments largely and significantly reduced the dormancy period for all the cultivars in all growing season, with an average $65 \%$ reduction $\left(1906\right.$ to $669{ }^{\circ} \mathrm{C}$ ). Treatments had the greatest impact on the cultivar Balatoni rózsa, with an average $33 \%$ reduction of dormancy, while they had the least impact on the cultivar Démon, with an average $25 \%$ reduction. We did not observe significant relationship between cultivar maturity type and the reduction of tuber dormancy. We found that the weather conditions of growing period influence the duration of dormancy and the efficiency of chemical treatments.
\end{abstract}

Keywords Chemical treatment · Gibberellic acid · Rindite $\cdot$ Solanum tuberosum $\cdot$ Tuber dormancy breaking

Zsolt Polgár

polgar.zsolt@szie.hu

Ádám Esztergályos

esztergalyos.adam@szie.hu

1 Potato Research Centre, Szent István University, Deák Ferenc Str. 16., Keszthely H-8360, Hungary 


\section{Introduction}

Tuber dormancy of potato cultivars is an important genetically determined trait that is largely influenced by environmental factors of the growing season. It partially determines the storage costs by influencing the storage temperature and the period of storage without sprout development (Wiersema 1985). Under temperate climatic conditions, longer dormancy is more advantageous, while in Mediterranean or subtropical conditions, where repeated planting within one calendar year or even permanent planting is possible, shorter dormancy is preferred (Struik and Lommen 1999). However, during seed multiplication programmes with multiple planting within one season and for rapid post-harvest quality testing of seed potatoes, shortening or breaking of dormancy is often needed (Coleman 1983; Struik and Wiersema 1999; Wróbel 2008).

Immediately after maturation, harvested tubers are in a state of deep or internal dormancy. They cannot sprout even under environmental conditions most favourable for growth (Van Ittersum 1992). Deep dormancy in the natural habitat of Solanum tuberosum species serves to protect tubers as organs of vegetative reproduction from unfavourable growth conditions (Suttle 2007; Aksenova et al. 2013). Tuber dormancy is a biochemically regulated process formed and maintained by abscisic acid (ABA) and ethylene, while indole acetic acid (IAA) and cytokinins (CK) are involved in the early stage of sprouting, and gibberellic acid (GA) contributes to sprout growth (Suttle 2004; Benkeblia et al. 2008).

There are significant differences between potato cultivars in the duration of internal dormancy, which is partly related to their maturity type. Cultivars with shorter season, early-maturity type have usually shorter dormancy, while longer-growing cultivars have longer dormancy periods, but the duration of tuber dormancy period depends primarily on genotype (Beukema and van der Zaag, 1979; Zarzyńska 2004; Bamberg 2010). Several external factors can also influence the length of dormancy within the same cultivar, such as the amount of temperature during the growing season (Tor 2011; Tiemens et al. 2013) and abiotic stress on the mother plant, e.g. heat shock and periodic water deficiency (Burton 1989; Ezekiel and Singh 2003; Zarzyńska 2004). Recently, Muthoni et al. (2014) published a summary publication on the regulation of potato tuber dormancy. Based on their results, dormancy is a complex trait that is influenced by the genetic background, stage of tuber development, environmental and management factors during tuber growth and storage. Dormancy is not related to earliness of cultivars, so it is possible to breed latematuring cultivars with short dormancy and early cultivars with long dormancy. Within the same cultivar, immature tubers usually have a longer post-harvest dormancy than tubers harvested at maturity. High temperatures, low soil moisture and low soil fertility during tuber growth accelerate physiological development and thus reduce the dormant period. Also, high storage temperature accelerates the physiological ageing processes, thus reducing dormancy. These differences can be up to several weeks. In addition, tuber dormancy can be influenced by chemical treatments.

Numerous ways for chemical regulation of dormancy duration have been developed. For example, tuber treatment with GA (Struik and Wiersema 1999; Hartmann et al. 2011; Hassani et al. 2014; Nasiruddin et al. 2016; Wróbel et al. 2017), Rindite, and combinations with GA (Bryan 1989), benzyl-adenine (BA) (Majeed and Bano 2006), 
bromoethane (Coleman 1983; Alexopoulos et al. 2009), or thiourea (Hosseini et al. 2011; Hassani et al. 2014) favours dormancy breaking. In addition, dormancy can be shortened by other treatments like heat and cold shock (Wurr and Allen 1976; Harkett 1981; van Ittersum and Scholte 1992) and mechanical treatments (Nasiruddin et al. 2016). However, the efficiency of these methods is strongly dependent on genotype (Majeed and Bano 2006; Suttle 2008; Hosseini et al. 2011; Hassani et al. 2014; Nasiruddin et al. 2016; Wróbel et al. 2017). Tuber dormancy of Hungarian cultivars originating from an intensive resistance breeding programme, and having several wild species in their genetic background, has not been investigated so far. Therefore, the aim of our experiments was the comparative study of chemical treatments for breaking the tuber dormancy of three new Hungarian potato cultivars to determine the most effective treatment that can be used on their seed.

\section{Materials and Methods}

The experiment was conducted in the Storage Physiology Laboratory of the Potato Research Centre at Keszthely, with two early-maturity-type cultivars (Balatoni rózsa and Botond) and a medium early-maturity-type cultivar (Démon). The investigated cultivars have different internal dormancy periods, which were determined in advance (Esztergályos et al. 2018). The experiment was conducted in three consecutive growing periods, in the fall of 2016, 2017, and 2018. The propagation degree of the tested seed tubers used in the experiments was super elite (Pre-Basic 2). They derived from the second cultivation cycle of in vitro plantlet-based PBTC tubers grown in aphid proof net houses and stored for 14 days after harvest for skin hardening at $20{ }^{\circ} \mathrm{C}$ in the dark before treatments. All tubers of each cultivar came from the same source.

The following tuber treatments were applied: (1) control, no treatment; (2 to 4) soaking in an aqueous solution of GA at concentrations of 10, 50, and $100 \mathrm{ppm}$ for $1 \mathrm{~h}$ (Bryan 1989), (5 to 7) soaking in an aqueous solution of BA at concentrations of 20, 30, and 100 ppm for 1 day (Majeed and Bano 2006), (8) treated with Rindite (7-3-1 mixture of ethylene chlorohydrin, ethylene dichloride and carbon tetrachloride) for 2 days (the application rate was $210 \mathrm{~cm}^{3}$ of Rindite per $\mathrm{m}^{3}$ of air space) and (9) a combined Rindite + GA 100-ppm treatment (combined treatment) (Bryan 1989). The experiment was carried out in 4 replications with 15 tubers in each replicate.

The dormancy period was determined according to the method of Carli et al. (2016). The dormancy period was considered expired when at least one bud developed a 2mm-long sprout on the observed tuber. The examined tubers were stored under the optimal condition for sprouting, in darkness in growth room at $20{ }^{\circ} \mathrm{C}$ and $80 \%$ relative humidity (RH\%). Observations were made daily at the same time. Because temperature can greatly influence the rate of physiological ageing, storage duration needed for sprouting was expressed as the (sum of average daily, or total) accumulated temperature recorded from first storage day after harvest to beginning of sprouting. This sum of temperatures combines the length of the storage time (days) and the storage temperature $\left({ }^{\circ} \mathrm{C}\right)$, expressed as one mathematical value of the accumulated average daily temperatures. Thus, physiological age can be expressed as the sum of the accumulated temperatures: the higher the amount of storage temperature, the higher the physiological age (O'Brien et al. 1983). 
The environmental conditions of the growing seasons can have a significant effect on the internal dormancy. The meteorological data of the investigated growing seasons are illustrated by Fig. 1 and were derived from iMetos meteorological data collecting station (Pessl Instruments $\mathrm{GmbH}$ ) located in the immediate vicinity of the growing field. Data were prepared and sorted using Microsoft Office 2007, and statistical data were analysed by the IBM SPSS 22 software.

\section{Results}

Under untreated (control) conditions, the cultivar Balatoni rózsa had the longest dormancy averaged over the three experimental years $\left(2061{ }^{\circ} \mathrm{C}, 103\right.$ days), while Botond had the shortest dormancy $\left(1737{ }^{\circ} \mathrm{C}, 87\right.$ days). Cultivar Démon had $1918^{\circ} \mathrm{C}, 96$ days long dormancy period. Rindite and GA at concentrations of 50 and $100 \mathrm{ppm}$, as well as the combined treatments, significantly reduced $(P \leq 0.05)$ tuber dormancy in all the three growing seasons.

Based on the results of univariate analysis of variance (Table 1), the significance of the treatment-cultivar-growing season interaction is close to 0 , so it has a statistically significant effect on dormancy. Dual interactions are also all statistically significant. This means that not only the treatments but also the cultivars and growing seasons have significant effect on the results. Therefore, it is advisable to illustrate the results separately for each growing season and cultivar (Table 2).

In 2016, we observed a similar trend in the reduction of dormancy period for all cultivars as a result of treatments. Rindite, GA100 and combined treatments were the most effective. For each cultivar, all three treatments resulted in more than $40 \%$ reduction compared with the control (Fig. 2). According to the Duncan test, Rindite and combined treatments were the most effective for cultivars Botond and Démon. The GA100 treatment also greatly reduced the dormancy periods of these two cultivars. The effect of GA100 was significantly different from the most effective treatments (Rindite and combined), but in practice this difference was not considerable (Table 2). The GA100 and combined treatments were the most effective for the cultivar Balatoni

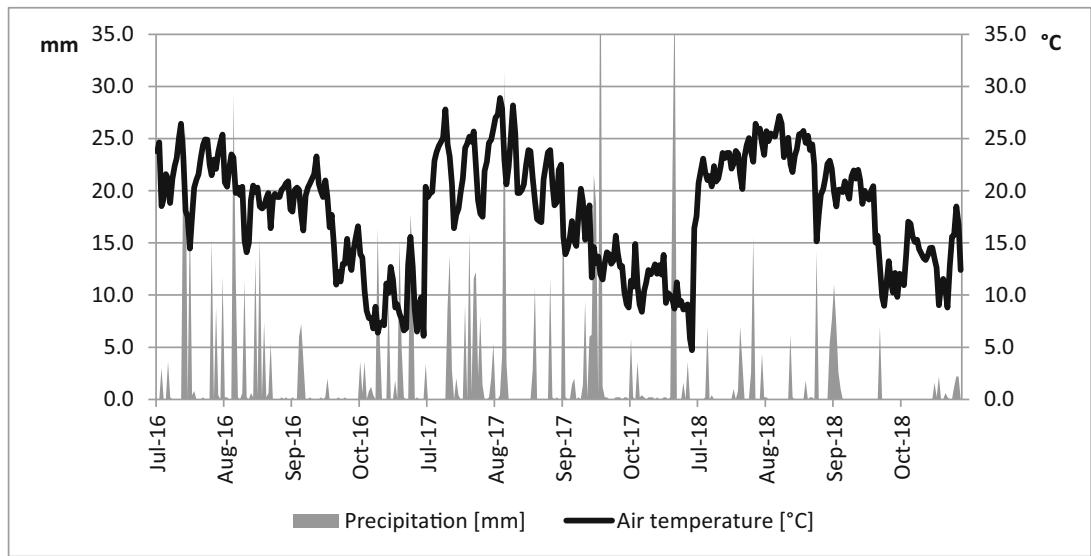

Fig. 1 Precipitation and air temperature during the growing period in 2016, 2017 and 2018 
Table 1 ANOVA for the effects of chemical treatments, cultivars and growing seasons on the tuber dormancy

\begin{tabular}{llllll}
\hline Source & Sum of squares & df & Mean squares & $F$ & Sig \\
\hline Treatment & 1072501396 & 8 & 134062675 & 11938 & 0.00 \\
Cultivar & 45889119 & 2 & 22944559 & 2043 & 0.00 \\
Growing season & 62853592 & 2 & 31426796 & 2799 & 0.00 \\
Treatment $\times$ cultivar & 38482425 & 16 & 2405152 & 214 & 0.00 \\
Treatment $\times$ growing season & 171551014 & 16 & 10721938 & 955 & 0.00 \\
Cultivar $\times$ growing season & 27060284 & 4 & 6765071 & 602 & 0.00 \\
Treatment $\times$ cultivar $\times$ growing season & 20528244 & 32 & 641508 & 57 & 0.00 \\
Error & 53667233 & 4779 & 11230 & & \\
\hline
\end{tabular}

rózsa, followed by GA50 and then Rindite. These differences (few percent only) were statistically significant, but not considerable in practice.

GA at lower concentrations (50 and $10 \mathrm{ppm}$ ) effectively reduced the dormancy of the cultivars, but to a lesser degree as the GA concentration decreased. For Botond and Démon the reduction was similar (35 and 30\%). For Balatoni rózsa, the GA50 treatment decreased the dormancy to a greater extent than Rindite, but the GA10 treatment was less effective than Rindite. In these cases, the reduction was more than $40 \%$ compared with the control (Fig. 2).

BA did not have a considerable effect on dormancy period at any concentration in any cultivar. We observed that with increasing concentration, it decreased the dormancy to a lesser extent, but this tendency was not always statistically significant. There was no significant difference in the BA treatments for Démon, compared with the control. For Balatoni rózsa and Botond, we found statistically significant differences, but in practice, none of them was considerable.

Rindite and combined treatments not only greatly reduced the dormancy, but also synchronised the sprouting of tubers. In contrast, BA treatments resulted in a prolonged and uneven sprouting (Fig. 3).

In 2017, a similar trend was observed in the reduction of dormancy for the tested cultivars. The dormancy period of each cultivar was longer under untreated conditions compared with the previous growing season, and differences in treatment efficiency were also observed (Table 2). The stronger effect of Rindite and the combined treatment was also salient. Both treatments reduced the dormancy to a much higher extent than in the previous year, about $80 \%$ compared with the control. This year again, Rindite, GA100 and combined treatments had the greatest impact on dormancy reduction for all cultivars (Fig. 2 ). The GA100 was more efficient than in 2016, but less effective than Rindite and combined treatments this year.

For the cultivar Balatoni rózsa, Rindite and combined treatments were the most effective, with similar reductions in dormancy ( $80 \%$ compared with the control). GA100 and GA50 treatments reduced dormancy by $60 \%$. For cultivars Botond and Démon, Rindite and combined treatment were also the most effective with about $80 \%$ reduction. The GA100 treatment also effectively reduced the dormancy of these cultivars (by $40 \%$ for Botond and $50 \%$ for Démon), but this year, the difference 


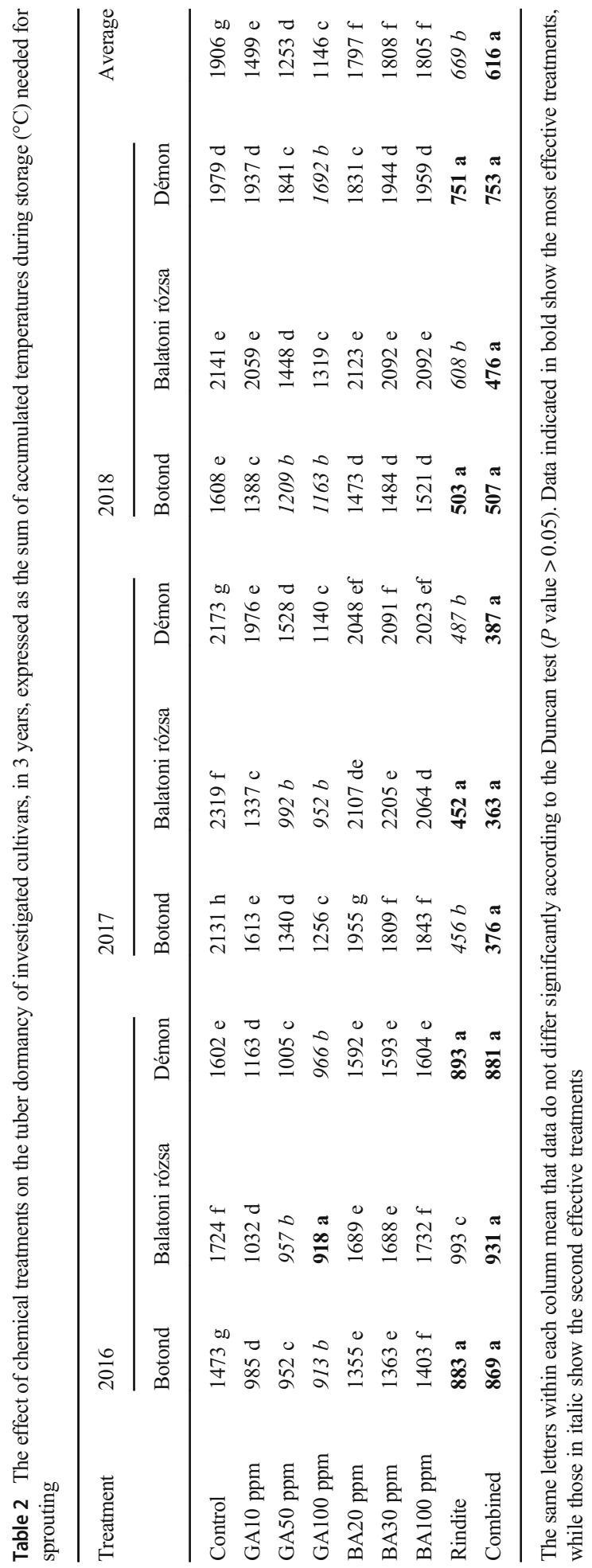




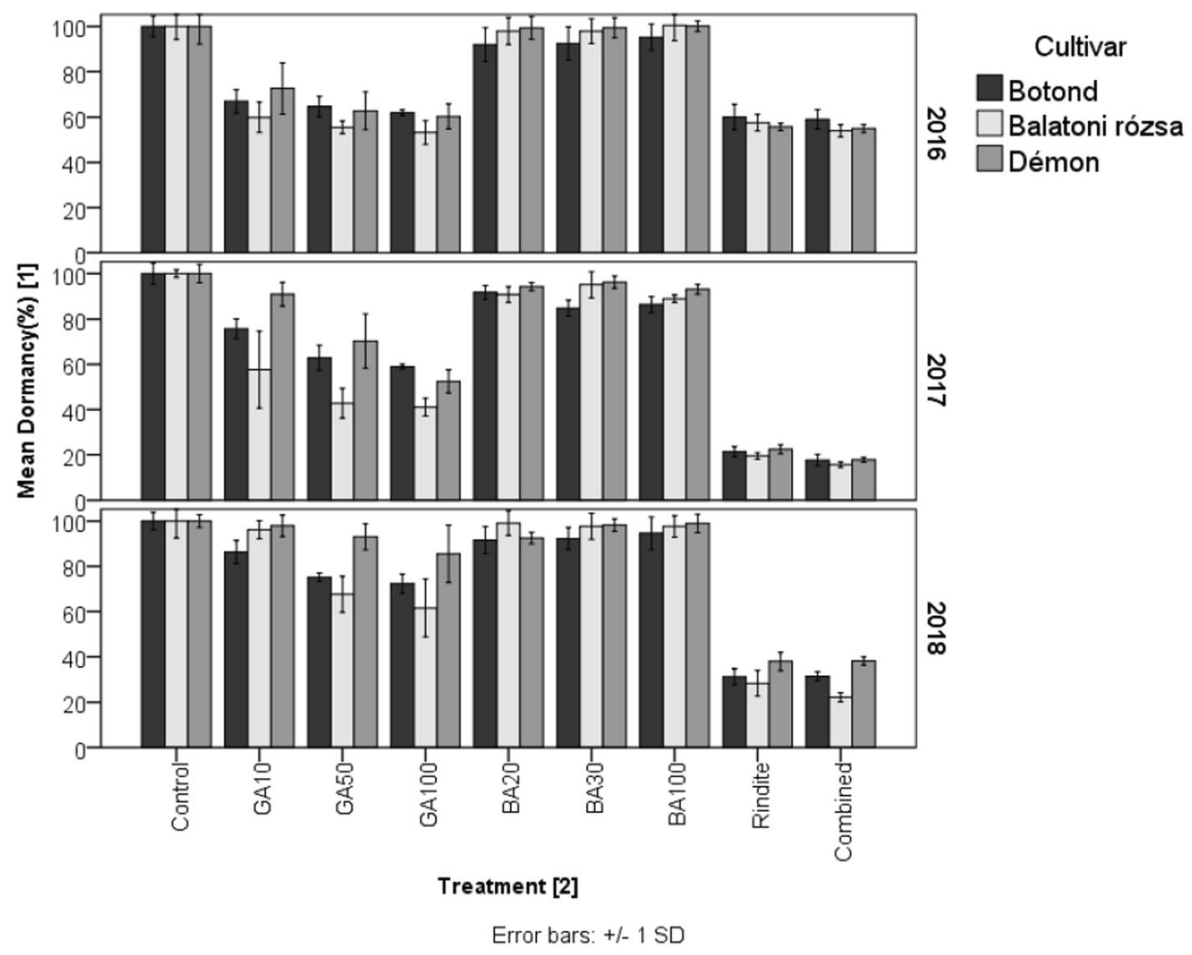

Fig. 2 The effect of chemical treatments on the tuber dormancy of the investigated cultivars. (1) Results are expressed as an average percentage of the control treatment (control is $100 \%$ for all the cultivars). Data comprises the mean values for all treatments. (2) Chemical treatments

between the treatments was greater. The reduction from GA treatments was directly proportional to the increasing concentration (Fig. 2).

Again, BA treatments did not greatly influence the dormancy this year, but to a statistically higher extent than the previous year. The difference was significant in each concentration for all three cultivars compared with the control. Between BA treatments, there were no significant differences for Démon, but we observed that the BA30 treatment reduced the dormancy the least $(4 \%)$ and the BA100 the most $(7 \%)$. For cultivar Balatoni rózsa, a similar tendency was observed, and for cultivar Botond, BA30 reduced dormancy the most (Table 2).

Rindite and combined treatments had the lowest range in this growing season and these treatments again reduced the dormancy the most effectively. Treated tubers sprouted almost simultaneously. For GA treatments, we found a larger range in data compared with the previous year and the treatments resulted in a prolonged sprouting.

BA treatments did not result in prolonged sprouting this year, and the range of data measured was similar to that of the control (Fig. 3).

As in the previous year, in 2018, application of Rindite and its combination with GA100 were the most effective treatment and reduced the dormancy period up to about $70 \%$ for all tested cultivars, compared with the control (Fig. 2). This year the internal dormancy of the cultivars was shorter than in the previous growing season, but longer 


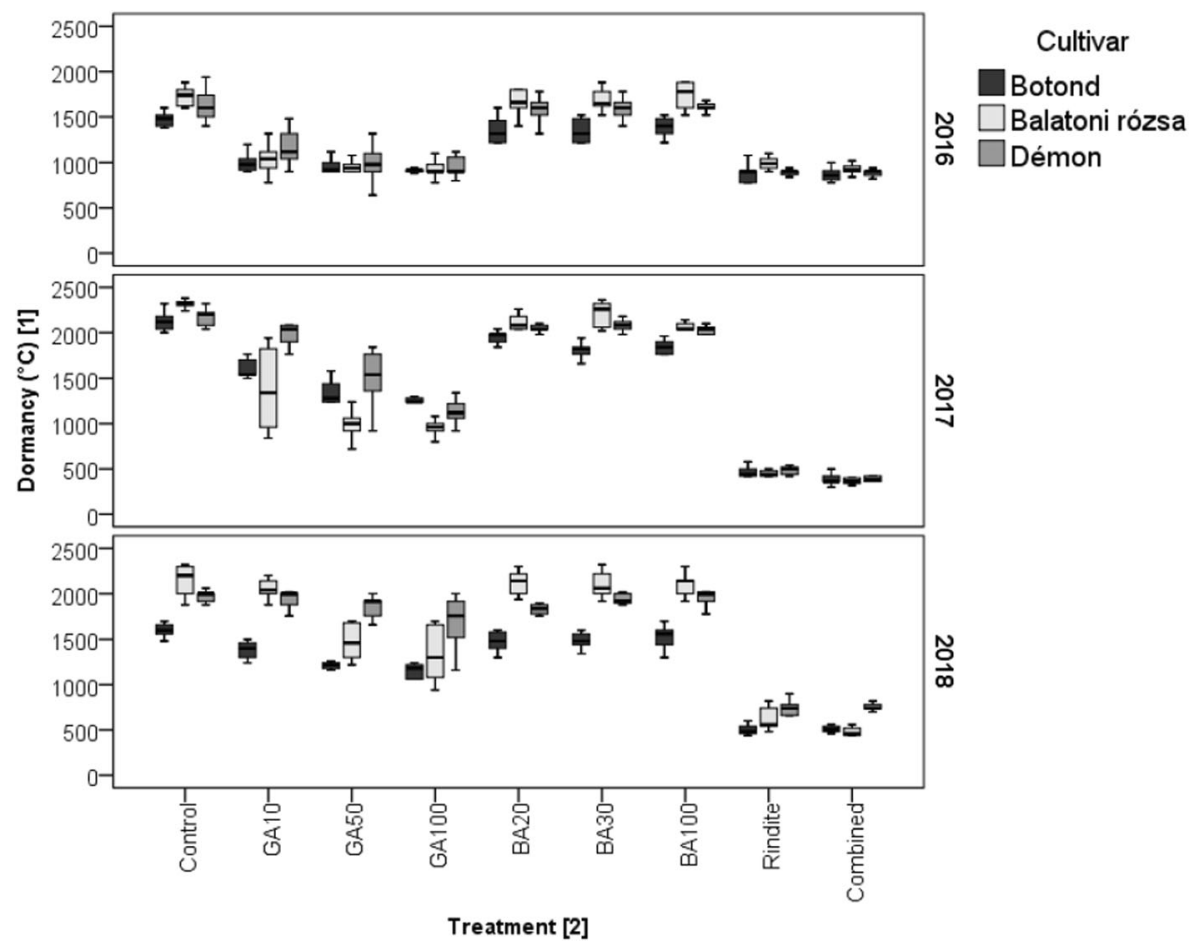

Fig. 3 Variability of data collected for chemical treatments on the tuber dormancy of investigated cultivars. Error bars represent the range of data (from minimum to maximum), boxes represent the interquartile range, the thick line inside the box represents the median. (1) Results are expressed as the sum of accumulated temperature during storage $\left({ }^{\circ} \mathrm{C}\right) .(2)$ Chemical treatments

than in 2016. The efficiency of the treatments was altered too. GA treatments reduced dormancy to a much lesser extent than in the previous growing seasons (Table 2). The highest concentration of GA (100 ppm) reduced dormancy by only $30 \%$ on average, compared with the control.

For the cultivar Balatoni rózsa, the combined treatment was the most effective with a reduction of $80 \%$ compared with the control. The Rindite treatment differed significantly from combined, which reduced the dormancy by $70 \%$. In this year, GA100 reduced the dormancy by $40 \%$ and GA50 by $30 \%$ while the result of GA10 treatment was not statistically different from the control (Fig. 2). Cultivars Botond and Démon responded similarly to the treatments this year. Rindite and combined treatments reduced dormancy to the same extent, $70 \%$ for Botond and $60 \%$ for Démon compared with the control. This means a considerable reduction compared with 2016's results, but a smaller reduction compared with the results of 2017 (Table 2). GA100 reduced dormancy by about $30 \%$ for both cultivars. For Botond, the GA50 treatment also reduced it by $25 \%$ compared with the control, but for Démon, the reduction was only $7 \%$ at this concentration. GA10 treatment did not greatly influence the dormancy of any cultivars, the result being statistically identical to the control for Démon (Fig. 2). This year again, the reduction from GA treatments was directly proportional to the increasing concentration. 
BA treatments had a similar effect this year to 2016. There was no large effect on either cultivar's dormancy, and in most cases, we did not find a significant difference from the control. For cultivars Botond and Démon, as before, with increasing BA concentration, dormancy was reduced to a lesser extent, and treatments reduced it by only $3 \%$ on average (Table 2 ).

Rindite and combined treatments resulted in the lowest deviation in the range of data, similarly to the previous year, while these treatments reduced dormancy the most effectively. BA treatments did not cause prolonged sprouting this year, and the range of data was similar to the control. However, in the case of GA treatments, we found a larger range compared with the previous years (Fig. 3).

\section{Discussion}

Our current data confirmed our previous results (Esztergályos et al. 2018) that internal dormancy of the examined cultivars is significantly different and the length of their dormancy period is not related to their maturity type. The cultivar Balatoni rózsa had the longest dormancy, while Botond with an identical maturity type had the shortest one. The cultivar Démon having a mid-season maturity type showed an intermediate dormancy length. These data are in agreement with findings of Beukema and van der Zaag (1979), Zarzyńska (2004) and Bamberg (2010) that internal tuber dormancy is largely genotype dependent and it is not directly related to maturity type.

The weather conditions of the growing season of test years may have influenced the cultivars' internal dormancy and the effectiveness of the treatments applied (Fig. 1). However, the analysis of the meteorological data did not allow any clear conclusions to be drawn.

Four of the applied treatments (Rindite, Combined, GA100 and GA50) significantly reduced the dormancy period for all three cultivars in all growing seasons. However, GA at 10 ppm concentration was not effective in 2018 and did not result in statistically significant reductions. BA treatments were significantly less effective than the other treatments with an average reduction of $6 \%$ that is negligible in practice. This finding is in contrast with the results of Majeed and Bano (2006) who got significant dormancy reduction after application of $40 \mathrm{ppm}$ BA in case of two mid-season cultivars (50 and $40 \%$ shortening for Diamant and Desirée, respectively). However, from that publication, the antecedents of treated tubers were not indicated so the achieved dormancy reduction from the untreated 35 and 54 days to 17 and 31 days is hard to compare with our ones where the basic dormancy of the tested cultivars was much longer.

Based on the average treatment effectiveness, chemical treatments influenced the reduction of dormancy of Balatoni rózsa the most (average 33\%). They had the smallest impact on the dormancy of Démon (average 25\%). Based on comparing treatments to each other, Botond was the most susceptible to treatments in all growing seasons, with each treatment significantly reducing dormancy. For the other cultivars, there were treatments that significantly did not effect the dormancy period, mainly BA treatments and in $2018 \mathrm{GA}$ at $10 \mathrm{ppm}$.

Botond and Démon responded similarly to the treatments in each year, but the reaction of Balatoni rózsa differed from 1 year to the other. The effect of Rindite and combined treatments was extremely high in 2017 and 2018 for this cultivar. The 
amount of heat absorbed by the mother plants was higher in these years. Consequently, we suppose there was a correlation between the physiological age of the tubers and dormancy period. The physiological age of Balatoni rózsa tubers may have been more strongly influenced by environmental factors than the other two cultivars.

In general, the combined treatment as the average of 3 years resulted in a $3 \%$ shorter dormancy period than Rindite alone, so the effects of GA100 and Rindite combine, but Rindite is the dominant component of the combined treatment. In 2017 and 2018, the reduction effect of Rindite and combined treatments was considerable, whereas GA treatments were less effective. Therefore in the case of investigated cultivars, the use of GA in this combination and concentration to break dormancy is not necessary.

In order to better understand the differences between cultivars, seasons, applied treatments and their interaction, more examinations are needed.

Author Contribution Both authors contributed to the study conception and design. Material preparation, data collection and analysis were performed by Ádám Esztergályos. The first draft of the manuscript was written by Ádám Esztergályos, while Zsolt Polgár commented on it critically. The authors revised and prepared the final version together. Both authors read and approved the final manuscript.

Funding Open access funding provided by Szent István University.

\section{Compliance with Ethical Standards}

Conflict of Interest The authors declare that they have no conflict of interest.

Human and Animal Rights This article does not contain any studies with human or animal subjects performed by any of the authors.

Open Access This article is licensed under a Creative Commons Attribution 4.0 International License, which permits use, sharing, adaptation, distribution and reproduction in any medium or format, as long as you give appropriate credit to the original author(s) and the source, provide a link to the Creative Commons licence, and indicate if changes were made. The images or other third party material in this article are included in the article's Creative Commons licence, unless indicated otherwise in a credit line to the material. If material is not included in the article's Creative Commons licence and your intended use is not permitted by statutory regulation or exceeds the permitted use, you will need to obtain permission directly from the copyright holder. To view a copy of this licence, visit http://creativecommons.org/licenses/by/4.0/.

\section{References}

Aksenova NP, Sergeeva LI, Konstantinova TN, Golyanovskaya SA, Kolachevskaya OO, Romanov GA (2013) Regulation of potato tuber dormancy and sprouting. Russ J Plant Physiol 60:301-312

Alexopoulos AA, Aivalakis G, Akoumianakis KA, Passam HC (2009) Bromoethane induces dormancy breakage and metabolic changes in tubers derived from true potato seed. Postharv Biol Technol 54: $165-171$

Bamberg J (2010) Tuber dormancy lasting eight years in the wild potato Solanum jamesii. Am J Pot Res 87: $226-228$

Benkeblia N, Alexopoulos AA, Passam HC (2008) Physiological and biochemical regulation of dormancy and sprouting in potato tubers (Solanum tuberosum L.). Fruit Veg Cereal Sci Biotech 2:54-68

Beukema HP, van der Zaag DE (1979) Dormancy and sprout growth. In: Potato improvement: some factors and facts. Wageningen, International Agricultural Centre, pp 26-36 
Bryan JE (1989) Breaking dormancy of potato tubers. CIP Research Guide 16. International Potato Center, Lima, pp 6-9

Burton WG (1989) Dormancy and sprout growth. In: The potato, 3rd edn. Longman Scientific \& Technical, Essex, pp 470-504

Carli C, Mihovilovich E, Bonierbale M (2016) Procedures for standard evaluation and data management of advanced potato clones. Module 4: assessment of dormancy and sprouting behaviour of elite and advanced clones. International Cooperators' Guide, Lima (Peru), International Potato Center, p 31

Coleman WK (1983) An evaluation of bromoethane for breaking tuber dormancy in Solanum tuberosum L. Am J Pot Res 60:161-167

Esztergályos Á, Polgár Zs, Cernák I (2018) Investigation of tuber dormancy period of potato varieties bred at Keszthely. XXIV. Scientific Day of Plant Breeding, Budapest, March 6. 2018. In: Book of Abstracts, (ed. Karsai I and Polgár Zs), pp 55. (in Hungarian)

Ezekiel R, Singh B (2003) Influence of relative humidity on weight loss in potato tubers stored at high temperatures. Indian J Plant Physiol 8:141-144

Harkett PJ (1981) External factors affecting length of dormant period in potatoes. J Science Food Agric 32: $102-103$

Hartmann A, Senning M, Hedden P, Sonnewald U, Sonnewald S (2011) Reactivation of meristem activity and sprout growth in potato tubers require both cytokinin and gibberellin. Plant Physiol 155:776-796

Hassani F, Zareian A, Rezvani E (2014) Effects of chemical treatments on dormancy breaking and some sprouting characteristics of two potato cultivars in different tuber sizes. Euro J Exp Bio 4:98-102

Hosseini MB, Afshari RT, Salimi K (2011) Breaking dormancy of potato minitubers with thiourea. Potato J 38:9-12

Majeed A, Bano A (2006) Role of growth promoting substances in breaking potato (Solanum tuberosum L.) tuber dormancy. J Agri Soc Sci 2:175-178

Muthoni J, Kabira J, Shimelis H, Melis R (2014) Regulation of potato tuber dormancy: a review. Aust J Crop Sci 8:754-759

Nasiruddin M, Khatun R, Haydar FMA, Imtiaj A, Alam MF (2016) Effect of physical and chemical treatments on sprouting of dormant potato tubers. Plant Envir Dev 5:24-27

O'Brien PJ, Allen EJ, Bean JN, Griffith RL, Jones SA, Jones JL (1983) Accumulated day-degrees as a measure of physiological age and the relationships with growth and yield in early potato varieties. J Agri Sci 101:613-631

Struik PC, Lommen WJM (1999) Improving the field performance of micro and mini-tubers. Potato Res 42: 559-568

Struik PC, Wiersema SG (1999) Seed potato technology. Wageningen, Wageningen Pers, pp 95-134

Suttle JC (2004) Physiological regulation of potato tuber dormancy. Am J Pot Res 81:253-262

Suttle JC (2007) Dormancy and sprouting. In: Vreugdenhil D (ed) Potato biology and biotechnology: advances and perspectives. Elsevier, Amsterdam, pp 287-309

Suttle JC (2008) Effects of synthetic phenylurea and nitroguanidine cytokinins on dormancy break and sprout growth in Russet Burbank minitubers. Am J Pot Res 85:121-128

Tiemens HM, Delleman J, Eising J, Lammerts ET, Van B (2013) Potato breeding. A practical manual for the potato chain. In: Aardappelwereld, The Hague, p 148

Tor JJ (2011) Influence of temperature and day-length on dormancy in seed potato cv. 'Asterix'. Euro J Plant Sci Biotech 5:55-61

Van Ittersum MK (1992) Variation in the duration of tuber dormancy within a seed potato lot. Potato Res 35 : 261-269

Van Ittersum MK, Scholte K (1992) Shortening dormancy of seed potatoes by storage temperature regimes. Potato Res 35:389-401

Wiersema SG (1985) Physiological development of potato seed tubers. International Potato Center, Lima, p 16

Wróbel S (2008) Early dormancy breaking of tubers in fast virus diagnostic for new potato cultivars. Prog Plant Prot 48:552-555

Wróbel S, Kessy J, Treder K (2017) Effect of growth regulators and ethanol on termination of dormancy in potato tubers. Am J Pot Res 94:544-555

Wurr DCE, Allen EJ (1976) Effects of cold treatments on the sprout growth of three potato varieties. J Agri Sci $86: 221-224$

Zarzyńska K (2004) The length of tuber dormancy period in new potato cultivars. Biuletyn IHAR 232:5-14

Publisher's Note Springer Nature remains neutral with regard to jurisdictional claims in published maps and institutional affiliations. 